\title{
Giant hand osteolipoma: Case Report
}

\section{Osteolipoma gigante de mano: Relato de Caso}

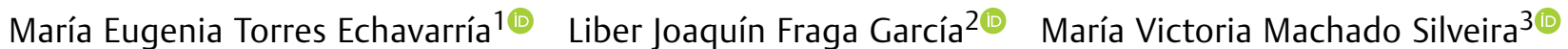

1 Plastic Surgery Resident, Hospital de Clínicas, Montevideo, Uruguay

2 Plastic Surgeon, Plastic Surgery Assistant Chair, Hospital de Clínicas, Montevideo, Uruguay

${ }^{3}$ Residente de Cirugía Plástica, Hospital Pasteur, Montevideo, Uruguay

\author{
Address for correspondence María Eugenia Torres Echavarría, MD, \\ Residente de Cirugía Plástica, Hospital de Clínicas, Montevideo, \\ Uruguay (e-mail: mariaeugeniatorres@outlook.com).
}

Rev Iberam Cir Mano 2021;49:74-78.

\begin{abstract}
Hand lipomas are rare in the hand, and they account for less than $1 \%$ of tumors.

Keywords

- lipoma

- osteolipoma

- ossifying lipoma

- hand

Resumen

Palabras clave

- lipoma

- osteolipoma

- lipoma osificante

- mano Osteolipoma is a rare variant of lipoma that is associated with bone metaplasia. It presents as a painless tumor that can cause symptoms when compressing adjacent structures. Magnetic resonance imaging (MRI) is the imaging study of choice. The treatment is surgical resection, with no recurrences being reported. We present the case of a patient with a giant subfascial hand osteolipoma, which, to the best of our knowledge has not yet been reported in the literature.

Los lipomas son infrecuentes en la mano, y representan menos del $1 \%$ de los tumores. El osteolipoma es una variante rara del lipoma que se caracteriza por presentar metaplasia ósea. Se presenta como una tumoración indolora que puede ser sintomática al comprimir estructuras adyacentes. La resonancia nuclear magnética (RNM) es el estudio de imagen de elección. El tratamiento es quirúrgico, no habiéndose relatado recurrencias. Presentamos el caso de una paciente con un osteolipoma gigante subfascial de mano, hasta ahora no relatado en la literatura.
\end{abstract}

\section{Introduction}

Osteolipoma is a benign tumor, constituting a histological lipoma variant associated with bone metaplasia. It is exceedingly rare, accounting for less than $1 \%$ of all lipomas. ${ }^{1}$ It is even rarer in the hands, with only case reports in the literature..$^{2-4}$

The present study aims to describe a clinical case of a giant osteolipoma in the hand and to discuss its clinical presentation, imaging studies, different diagnoses, and treatment.

\section{Clinical Case}

The patient is a right-handed, 51-year-old woman who works as a maid. She presented a tumor for 10 years, which grew

received

June 12,2020

accepted

September 14, 2020 slowly and progressively, and had no history of trauma. In the previous few months, she also presented pain and paresthesia in the first and second fingers. A physical examination revealed a tumor at the level of the first commissure, with regular borders, $6 \mathrm{~cm}$ at its largest diameter, smooth surface, and firm elastic consistency. The tumor was adhered to deep planes but with no cutaneous changes ( - Fig. 1 ). The paired discrimination test results were altered for the first and second finger pulps at $8 \mathrm{~mm}$, with negative Tinel sign and no motor changes. The patient presented no palpable lymph-node enlargements.

A radiographical evaluation showed a tumor with calcifications in the first commissure extending to the second intermetacarpal space (-Fig. 2)

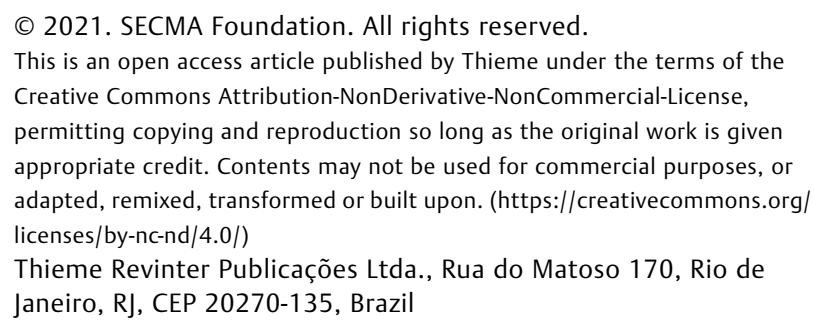




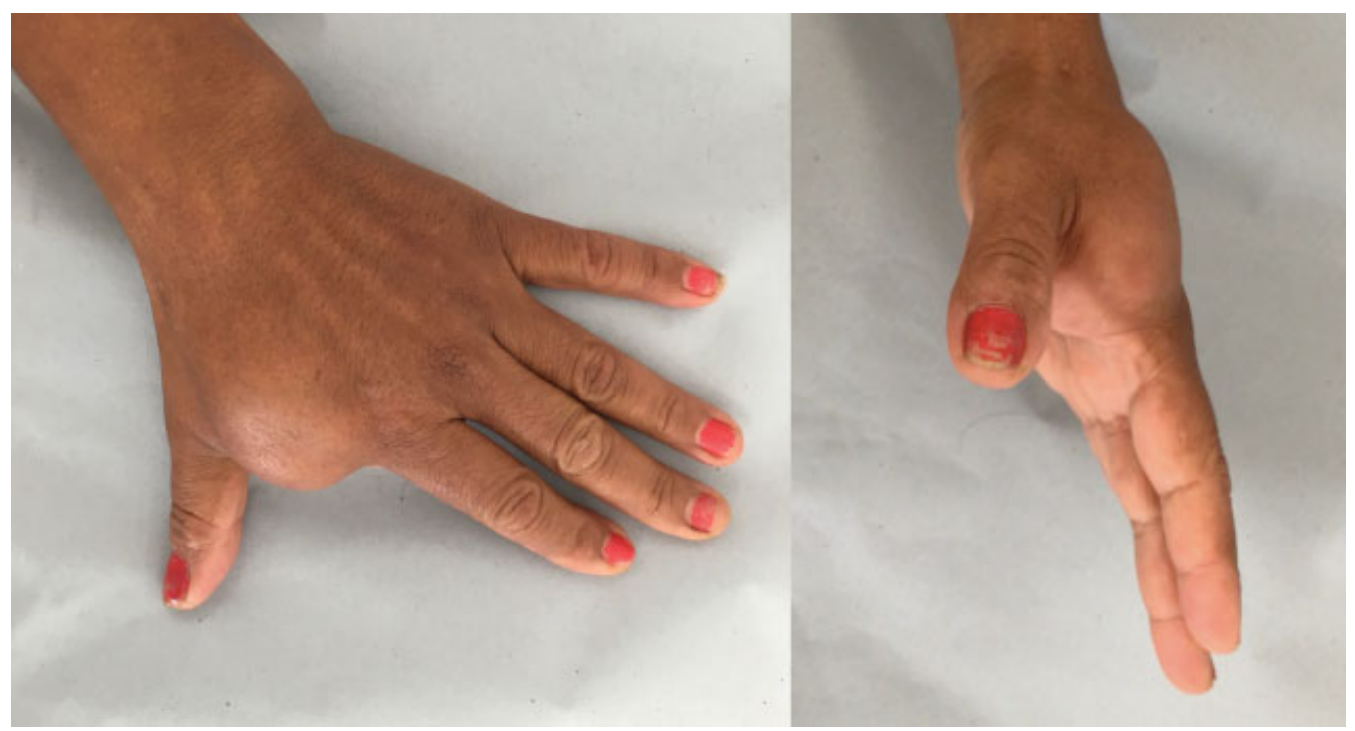

Fig. 1 Clinical image showing the tumor at the first interdigital commissure. Dorsal (left) and lateral (right) views.

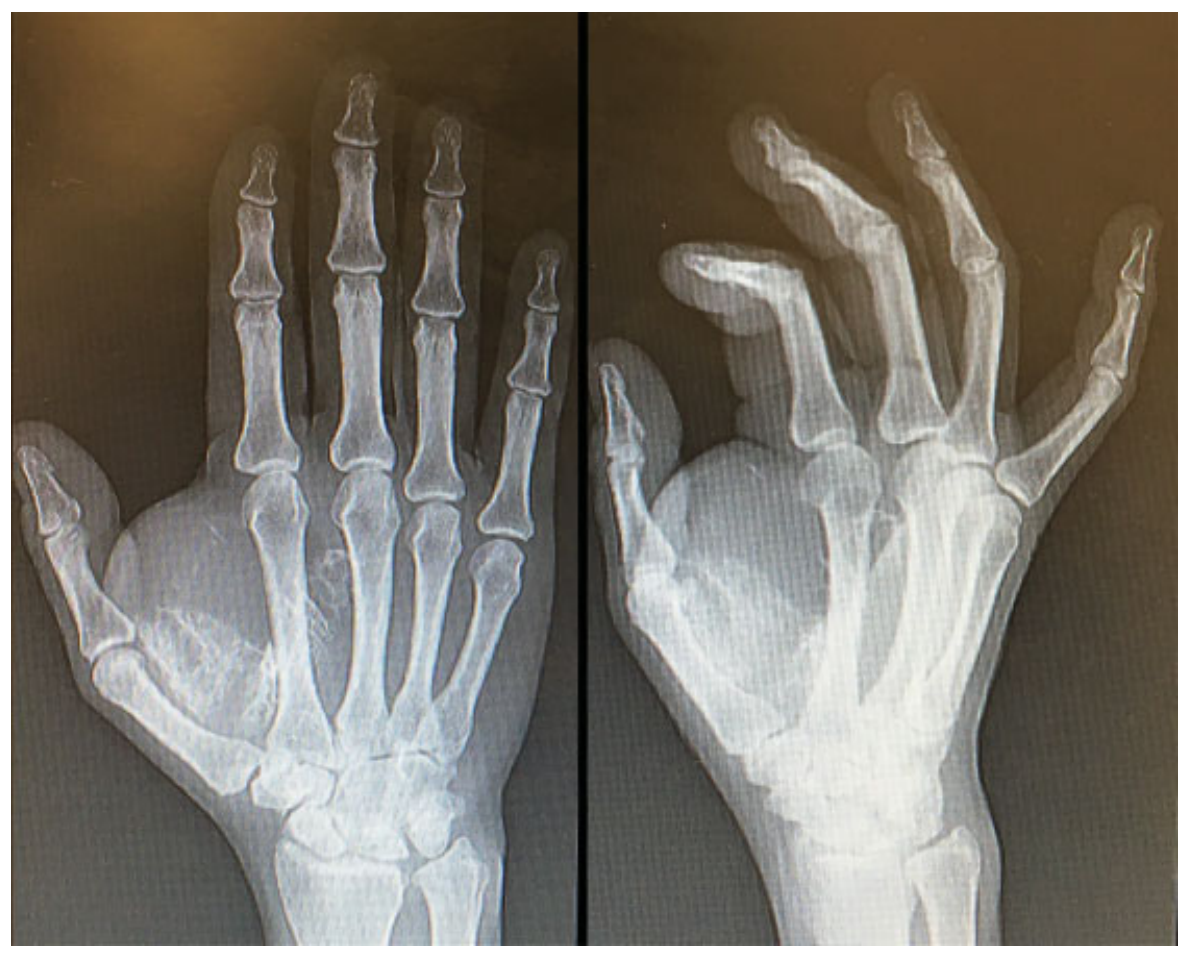

Fig. 2 Simple radiographs in anteroposterior (left) and oblique lateral (right) views showing a tumor with calcifications.

A magnetic resonance imaging (MRI) scan revealed a polylobulated tumor, with well-defined limits, $61 \mathrm{~mm}$ in length, $57 \mathrm{~mm}$ in width, and $39 \mathrm{~mm}$ in the anteroposterior direction. The tumor was located at the thenar region, at the level of the first interosseous space, deep into the regional muscles; it had a deep medial extension deep to the flexor tendons of the second and third fingers. The signal was similar to that of the adjoining fat tissue, with saturation in the fat-sat sequence; in addition, the tumor presented peripheral linear and punctate calcifications, with no contrast-medium enhancement. The report concluded that it was a lipoma with calcifications and no nodular areas with anomalous enhancement (-Fig. 3).

Under general anesthesia and in a bloodless surgical field, a dorsal approach centered on the tumor was performed ( - Fig. 4). A yellow polylobulated tumor was identified and resected. The tumor had heterogeneous features, including petrous sections, but with a clear 


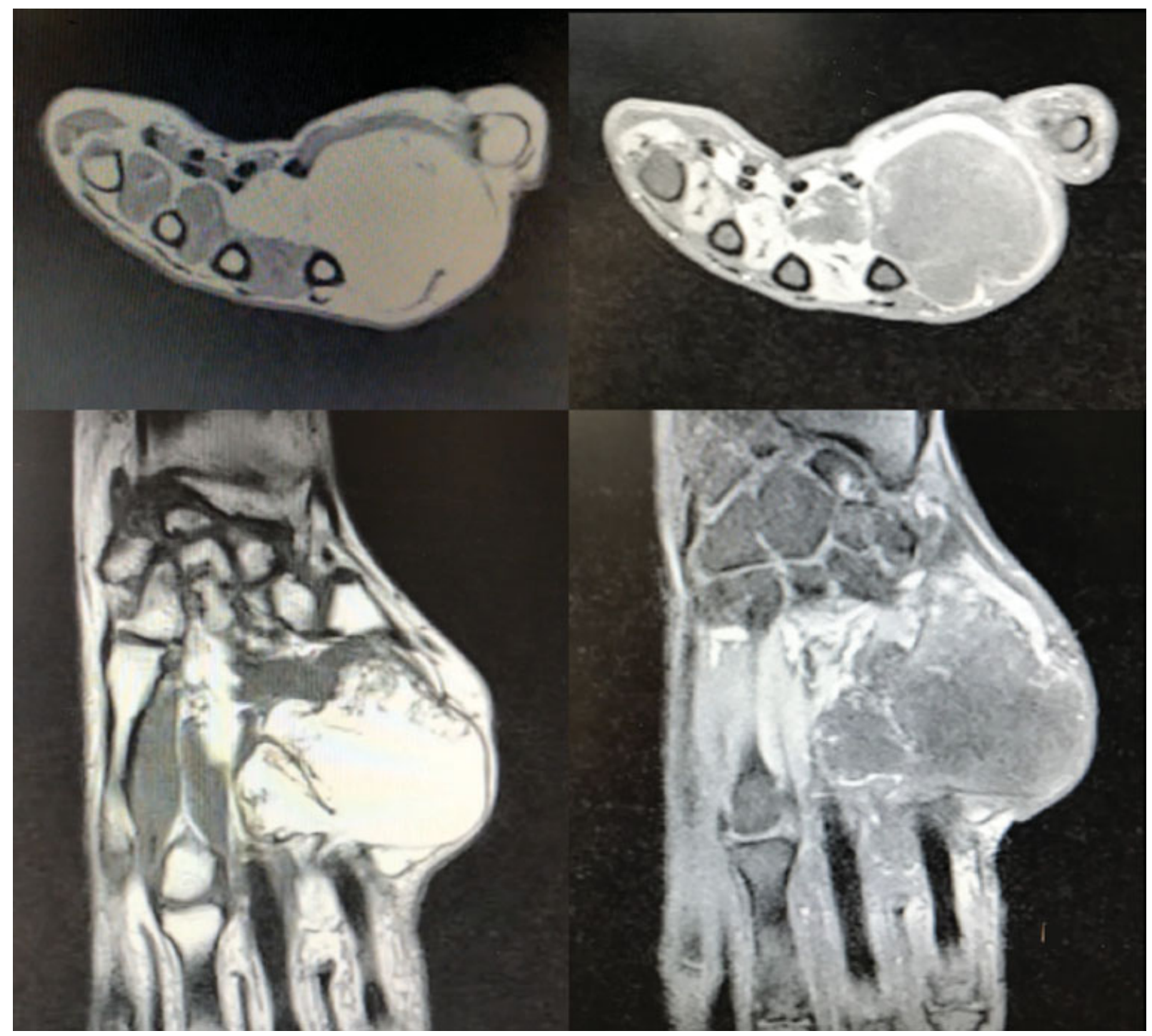

Fig. 3 Magnetic resonance imaging scan showing a well-delimited, polylobulated, subfascial tumor located at the thenar region and first interosseous space. It has a medial extension that dislocates the flexor tendons from the second and third fingers. The tumor is hyperintense in T1- and hypointense in T2-weighted images, and presents linear and punctate calcifications.

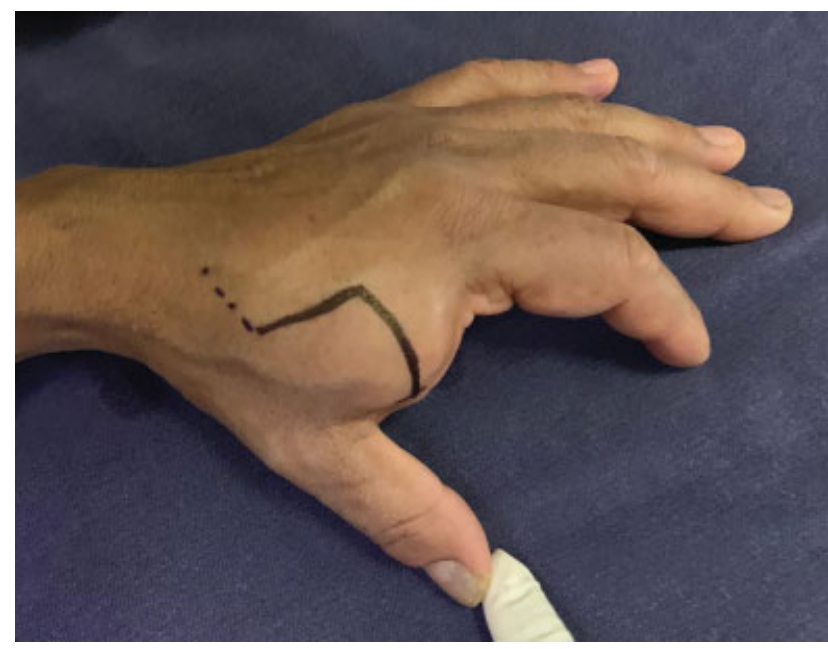

Fig. 4 Dorsal approach in zigzag over the first commissure.

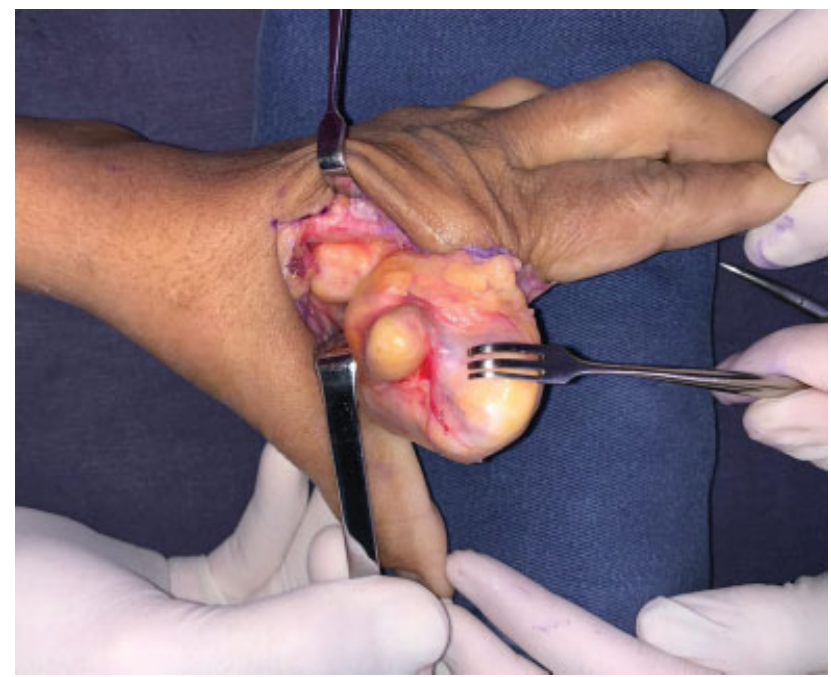

Fig. 5 Intraoperative image showing a well-delimited, polylobulated tumor. 


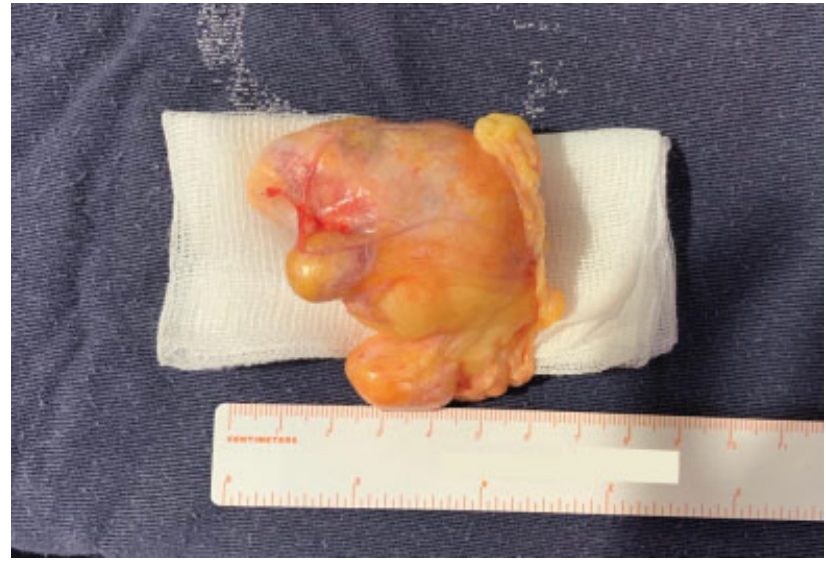

Fig. 6 Macroscopic appearance of the specimen. cleavage plane from the adjacent tissues (-Fig. 5). Dorsal sensitive nerve branches, that were not infiltrated, were identified and spared. There were no postoperative complications, with resolution of the paresthesia within 48 hours.

The pathological anatomy service reported a macroscopy piece measuring $62 \times 53 \times 41 \mathrm{~mm}$, presenting features of a well-delimited, polylobulated fat-cell tumor (-Fig. 6). The microscopic analysis revealed mesenchymal proliferation, composed of mature adipocytes, with no atypical necrosis, and accompanied by fibrous connective tissue tracts and focal areas of bone metaplasia (-Fig. 7).

At the 6-month follow-up, the patient presented a goodquality scar, no sensory deficit, good hand function, and no tumor recurrence (-Fig. 8).

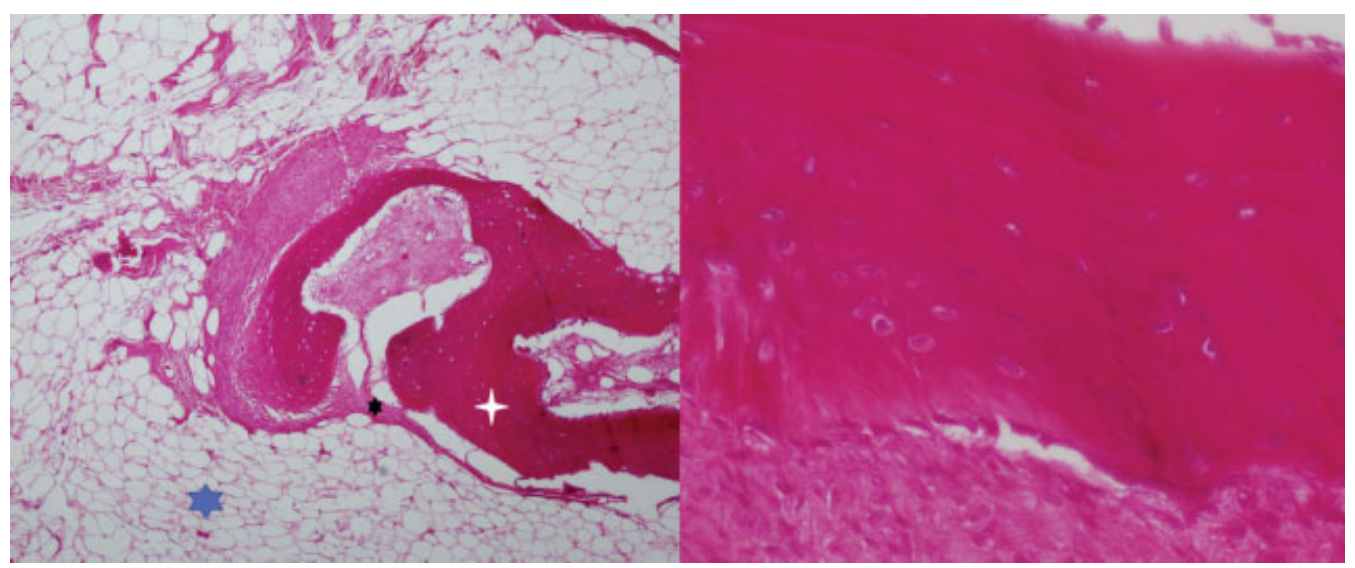

Fig. 7 Microscopy analysis, hematoxylin-eosin stain. Left (x40): proliferation mainly composed of mature adipocytes (blue), fibrous connective tissue tracts (black), and focal areas of bone metaplasia (white). Right (x200): area of bone metaplasia.

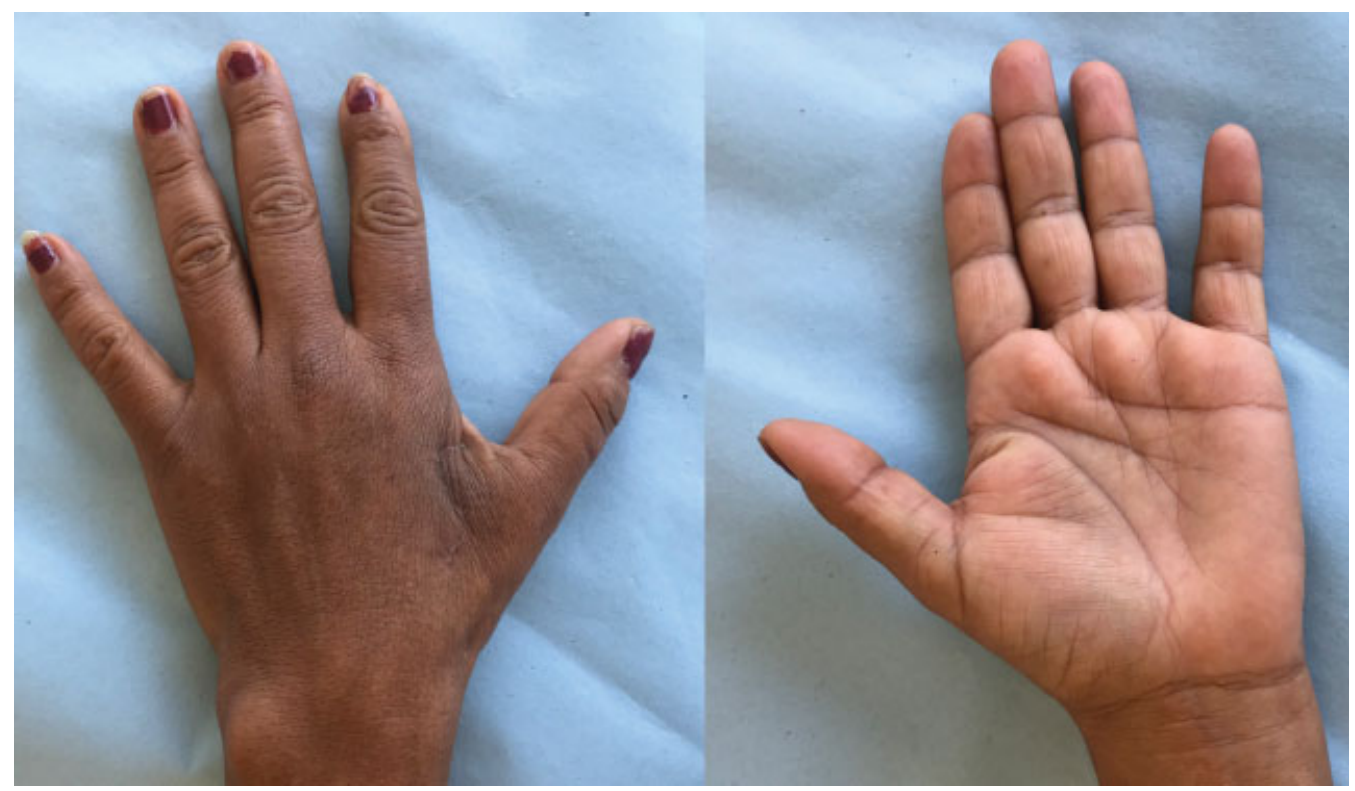

Fig. 8 Outcome six months after surgery. 


\section{Discussion}

Lipomas are the most common soft-tissue tumors in adults, but they are rare in the hands.

A lipoma is deemed giant when presenting more than $5 \mathrm{~cm}$ at its largest diameter. It is often subcutaneous, but it can also lie in the deep subfascial tissue. Deep lipomas can be intramuscular, intermuscular, or periosteal when located on bone surface.

Histologically, it is a benign, well-delimited tumor of mesenchymal origin, which is composed of mature adipocytes with no atypia. However, it may be associated with other mesenchymal tissues, which is reflected on its name (fibrolipoma, chondrolipoma, osteolipoma, myxolipoma, angiolipoma). ${ }^{5}$

An osteolipoma is the histological variant of the lipoma that presents bone metaplasia. It accounts for less than $1 \%$ of all lipomas.

Osteolipoma, ossifying lipoma and lipoma with bone metaplasia are terms used interchangeably in the literature. Some authors prefer calling it ossifying lipoma when adipose tissue is predominant. There are two theories regarding its pathogenesis. According to the first theory, the ossification foci originate from pluripotent mesenchymal cells present within the lipoma; the second and most accepted theory, however, states that ossification is secondary to repetitive trauma and ischemia, resulting in metaplasia of the preexisting fibrotic elements. ${ }^{6}$

Clinically, osteolipomas are painless tumors that cause symptoms due to the compression of adjacent structures. Most are located in the head and neck. ${ }^{7}$

Since it is a soft-tissue tumor with calcifications, differential diagnoses must include ossifying myositis, ossifying fibroma, teratoma, and low-grade liposarcoma; the latter is important because it is a malignant tumor of adipose origin with similar clinical and imaging features.

Ultrasonography may be a diagnostic study, revealing a heterogeneous, hyperechoic, calcified lesion. Computed tomography shows a hypodense, well-delimited lesion with hyperdense areas of calcifications. ${ }^{8}$

The MRI is the preferred imaging study. It is essential to differentiate lipomas from low-grade liposarcomas, with $100 \%$ of sensitivity and $83 \%$ of specificity in diagnosing this malignant tumor. The MRI has a specificity of $100 \%$ to diagnose simple lipomas, with slightly lower values for some lipoma variants, such as osteolipoma, chondrolipoma, angiolipoma or hibernoma. Upon observation, osteolipoma is a well-delimited tumor with fat consistency, and it is not enhanced by contrast medium; on the other hand, liposarcomas present thick fibrous septa, intralesional fatty nodules, a lower proportion of fat components, and are enhanced by contrast medium. ${ }^{9}$

The treatment consists of marginal resection of the lesion, with an anatomopathological analysis to confirm the diagnosis.

The prognosis is good, similar to that of lipoma, with no reported recurrences. ${ }^{10}$

\section{Conclusions}

Osteolipoma is an uncommon benign tumor that is rare in the hand. The MRI is the preferred imaging study. The surgical treatment is curative, and an anatomopathological analysis must be performed. No recurrences have been reported.

\section{Conflict of Interests}

The authors have no conflict of interests to declare.

\section{Acknowledgments}

Dr. Andrea Cristiani, Chair of Pathological Anatomy, Hospital de Clínicas, Montevideo, Uruguay.

\section{References}

1 Allen PW. Tumors and proliferations of adipose tissue. A Clinicopathologic Approach Masson Monographs in Diagnostic Pathology. Vol. 1;Masson Publishing USA Inc.New York1981

2 Bennani A, Saliou SS, Zizah S, et al. Une localisation inhabituelle d'un lipome ossifié juxtaosseux. À propos d'un cas. Chir Main 2013;32(02):113-116

3 Yang TH, Fong YC, Hsu HC, Jim YF, Chiang IP, Lin MJ. Re: ossifying lipoma of the hand. J Hand Surg Eur Vol 2008;33(01):82-83

4 Hopkins JD, Rayan GM. Osteolipoma of the hand: a case report. J Okla State Med Assoc 1999;92(11):535-537

5 Fletcher CDM, Bridge JA, Hogendoorn PCW. WHO Classification of Tumors of Soft Tissue and Bone. 4th ed. Lyon: IARC Press; 2013

6 Obermann EC, Bele S, Brawanski A, Knuechel R, Hofstaedter F. Ossifying lipoma. Virchows Arch 1999;434(02):181-183

7 Val-Bernal JF, Val D, Garijo MF, Vega A, González-Vela MC. Subcutaneous ossifying lipoma: case report and review of the literature. J Cutan Pathol 2007;34(10):788-792

8 Kwan Ip NS, Lau HW, Wong WY, Yuen MK. Osteolipoma in the Forearm. Case Report. J Clin Imaging Sci 2018;8(01):1-4

9 Gaskin CM, Helms CA. Lipomas, lipoma variants, and well-differentiated liposarcomas (atypical lipomas): results of MRI evaluations of 126 consecutive fatty masses. AJR Am J Roentgenol 2004; 182(03):733-739

10 Yang JS, Kang SH, Cho YJ, Choi HJ. Pure intramuscular osteolipoma. J Korean Neurosurg Soc 2013;54(06):518-520 